\title{
Thermoregulatory responses to repeated warm water immersion in subjects who are paraplegic
}

\author{
EM Gass ${ }^{*}, 1$ and GC Gass ${ }^{1}$ \\ ${ }^{1}$ School of Physiotherapy and Exercise Science, Faculty of Health Sciences, Griffith University, Queensland, Australia
}

Objective: To compare thermoregulatory responses to repeated warm water immersion $\left(39^{\circ} \mathrm{C}\right)$ between physically active subjects who are paraplegic or able-bodied in order to gain insight into rehabilitative and adaptive processes.

Methods: Five paraplegic (P) and six able-bodied (AB) males participated. $\dot{\mathrm{V}}_{2}$ peak was determined by open-circuit spirometry using a cycle ergometer (AB) and propelling a wheelchair on a motor driven treadmill (P). Subjects sat immersed to the nipple line in $39^{\circ} \mathrm{C}$ water for $60 \mathrm{~min}$ for 5 consecutive days. Pre- and post-test measurements included heart rate (HR), oesophageal temperature (Tes), sweat onset and rate (dew point hygrometry). Venous blood was obtained before, and during immersion to estimate changes in plasma volume.

Results: The $\mathrm{P}$ group was older and lighter than $\mathrm{AB}$ group $(P<0.05) . \dot{\mathrm{V}} \mathrm{O}_{2 \max }, \dot{\mathrm{V}} \mathrm{CO}_{2 \max }$ and $\dot{\mathrm{V}} \mathrm{E}_{\max }$ were significantly greater in $\mathrm{AB}$ group. $\mathrm{HR}$ at rest and after 60 min immersion was not significantly different between the groups pre- or post-test. Tes significantly increased after $60 \mathrm{~min}$ immersion in both groups, at both pre- and post-testing sessions. Post-test Tes after 60 min immersion (AB) was significantly less than Tes after $60 \mathrm{~min}$ of immersion pre-test. The $\Delta$ Tes (Tes 60 min-Tes 0 min) was significantly higher in AB group than the $\mathrm{P}$ group at prebut not post-testing. No significant changes in sweat onset or rate were found for the $A B$ or $\mathrm{P}$ groups during the pre- or post testing sessions. Significant expansion of plasma volume occurred during immersion in both groups, pre- and post-immersion sessions.

Conclusions: Repeated warm water immersion $\left(39^{\circ} \mathrm{C}\right)$ for $60 \mathrm{~min}$ per day for a total of 5 days did not produce a significant adaptive response in $\mathrm{P}$ group. In the $\mathrm{AB}$ group, Tes at the end of 60 min immersion was significantly lower after the adaptation period.

Spinal Cord (2001) 39, $149-155$

Keywords: oesophageal temperature; warm water immersion; plasma volume; spinal cord injury; paraplegia

\section{Introduction}

During exercise in the heat, thermoregulation in humans can be achieved by activating effector responses in proportion primarily to displacements in core temperature from the set point temperature. ${ }^{1}$ These responses are well described and include release of constrictor tone of superficial veins and resistance vessels in the skin, increase in skin and limb blood flow, onset of sweating, active vasodilation, and further increases in skin blood flow. ${ }^{1}$

Less well described are the physiological changes that occur in response to repeated exposures to heat via methods such as resting in a hot environment, eg sauna, being enclosed in a temperature controlled body suit or during warm water immersion. ${ }^{2-7}$

Repeated exposures to heat of sufficient intensity, frequency and duration can result in a lowered physiological strain for a given thermal stimulus.,

*Correspondence: E Gass, PMB 50, Gold Coast Mail Centre, QLD 9726, Australia
Lowered physiological strain is typically evidenced by lowered heart rate, skin and core temperature, increased plasma volume and earlier onset, and rate of sweating. ${ }^{10-15}$

The use of a variety of physiological stressors such as exercise, exercise in the heat, heating via water perfused suits, climatic chambers and warm water immersion have not only clouded our interpretations of the effects of repeated exposures to heat per se, but such studies have been conducted on subjects with intact autonomic, sensory and motor systems. Research into the effects of repeated exposure to heat in individuals with traumatic spinal cord injury is rare. ${ }^{16}$

Traumatic spinal cord injury results in disruption to autonomic, sensory and motor systems with the extent of disruption being dependent upon the level and completeness of the spinal cord injury. A complete lesion to the cervical cord results in lesion level dependent motor paralysis of muscles of the arms, 
trunk and legs, and absence of sensation of the skin over those areas. Below the level of the spinal cord lesion it is expected that there will be no centrally driven vasomotor or sudomotor activity, resulting in higher skin temperatures and a greater gain in core temperature (Tcore) when the person with a cervical cord lesion is thermally challenged. Traumatic injury to lower levels of the spinal cord (T10 and below), results in normal function above the spinal cord lesion and a reflex, non-centrally controlled response below the lesion level. As a result of injury to the spinal cord, significant disruptions to thermal homeostasis have been demonstrated at rest $^{6,17,18}$ and during exercise. ${ }^{19,20}$

The reduction in sudomotor and vasomotor function resulting from injury to the spinal cord, ${ }^{6,21,22}$ combined with a likely reduced total blood volume may lead to higher heat storage for a given thermal stimulus, thereby raising the risk of a heat related disorder. Indeed, passive heat has been reported to be responsible for approximately $3 \%$ of all deaths in people with spinal cord injury. ${ }^{23}$

The increasing participation of people with traumatic spinal cord injury in prolonged and often intense exercise and the clinical use of repeated exposure to high temperatures such as sauna $\left(90^{\circ} \mathrm{C}, 5 \%\right.$ to $10 \%$ $\mathrm{RH})$ to control spasticity, has raised the importance of establishing how those with traumatic spinal cord injury respond to repeated thermal stimuli, and whether any physiological adaptation occurs with repeated heat exposure. Given the paucity of data on whether individuals with traumatic spinal cord injury can adapt to repeated heat exposures, a useful starting point would be to investigate the effects of heat per se, before the combination of heat and exercise is considered.

Given also that many people with spinal cord injury undergo repeated rehabilitation sessions in warm water, and given the accessibility of this medium, the aim of the present experiment was to compare thermoregulatory responses to repeated warm $\left(39^{\circ} \mathrm{C}\right)$ water immersion between physically active subjects who are paraplegic and those who are able-bodied.

\section{Methods}

Five physically active paraplegic men and five physically active men (controls) volunteered to participate in the present study. The experimental procedures had been approved by the Institutional Ethics Committee. The men, who were paraplegic, were members of the same basketball team. Each subject participated in a familiarisation session including a demonstration of all intended procedures as well as an explanation of the possible risks and benefits of the proposed experiment. Having freely provided written consent, each subject was scheduled to visit the laboratory on eight occasions.

The first and second visits involved pre-testing and the eighth visit was a post-testing session. Visits 3 to 7 were consecutive daily heating sessions, with each subject immersed to the nipple line in $39^{\circ} \mathrm{C}$ water.

On the first visit each subject underwent a medical examination, standard anthropometry and an incremental exercise test to exhaustion. With the subject dressed in a nylon swimming suit and having voided, or with an emptied catheter bag, body mass was measured to the nearest $0.05 \mathrm{~kg}$. Skinfold thicknesses were measured at three sites (triceps, biceps and subscapular) and supine/standing height was measured using a stadiometer (Holtain, UK). For the subjects who were paraplegic, $\dot{\mathrm{V}}_{2}$ max and related variables were obtained by having each subject push his own basketball wheelchair on a motor driven treadmill to exhaustion using a protocol described by Gass and Camp. ${ }^{19} \dot{\mathrm{VO}}_{2}$ peak and related variables were obtained for the able-bodied subjects cycling on an electronically braked cycle ergometer (Siemens 380B, The Netherlands) until exhaustion. After a $3 \mathrm{~min}$ warm up at $30 \mathrm{~W}$, power on the cycle ergometer was increased $15 \mathrm{~W}$ every $30 \mathrm{~s}$ until the subject could not continue. Throughout the incremental exercise test, subjects breathed through a Hans Rudolph valve (No. 2700, USA) and the expired gas was passed through a pneumotach (Hewlett-Packard Model HP 47304A, USA) into a baffled mixing chamber. Oxygen and carbon dioxide analysers (Rapox and Capnograph, The Netherlands) continuously sampled mixed expired gas from the distal end of the mixing chamber. Every $30 \mathrm{~s}$ calculations were made of $\mathrm{O}_{2}$ uptake $\left(\dot{\mathrm{VO}}_{2} \mathrm{~L} \mathrm{~min}^{-1}, \mathrm{~mL} \mathrm{~min}^{-1} \mathrm{~kg}^{-1}\right.$ ), $\mathrm{CO}_{2}$ production $\left(\dot{\mathrm{V} C O} \mathrm{~L} \mathrm{~min}^{-1}, \mathrm{~mL} \mathrm{~min}^{-1} \mathrm{~kg}^{-1}\right.$ ), minute ventilation corrected to BTPS ( $\dot{\mathrm{VE}} \mathrm{L} \mathrm{min}{ }^{-1}$ ) and respiratory exchange ratio $(\mathrm{R})$. The analysers were calibrated with a mixture of chemically analysed gas and the pneumotach calibrated with a $3 \mathrm{~L}$ syringe before and after each exercise test. Heart rate (HR) was monitored continuously using a CM5 lead placement and recorded during the last $10 \mathrm{~s}$ of each min of exercise.

The second visit involved warm water immersion (pre-test) and occurred at approximately the same time of day for all subjects and within the week of the first visit. Each subject was weighed as described earlier and a calibrated temperature probe, using an integrated circuit transducer (AD590, USA), was inserted by each subject via the nose into the oesophagus (Tes) to a distance approximately $1 / 4$ standing/supine height. $^{20}$ A towel was positioned appropriately for each subject so saliva could be expectorated.

A small capsule $\left(13.4 \mathrm{~cm}^{2}\right)$, using the principle of dew-point hygrometry ${ }^{24}$ was attached to the centre of the forehead, using a broad elastic band, and sealed at the skin junction with a layer of petroleum jelly. Dry air flowed across the capsule at a rate to ensure evaporation of collected sweat on the Peltier device. From this capsule, dew-point temperature (Tdp) was monitored continuously and subsequently used to calculate and determine the onset and rate of 
forehead sweating. Tes and HR were also monitored continuously and recorded every $20 \mathrm{~s}$ during the immersion period.

A surflo catheter was inserted either into a vein on the dorsum of the hand, or on the lower $1 / 3$ of the extensor aspect of the forearm and patency was maintained by flushing with $15 \mathrm{IU} \mathrm{ml}^{-1}$ of sterile heparinised saline. Venous blood was withdrawn at the beginning of the pre-immersion period $(-10 \mathrm{~min})$, immediately before immersion $(0 \mathrm{~min})$, and after 30 and $60 \mathrm{~min}$ of immersion and subsequently analysed for hemoglobin $(\mathrm{Hb}){ }^{25}$ Hematocrit (Hct) was measured in triplicate with a microhematocrit centrifuge and not corrected for the plasma trapped in the packed erythrocytes nor for the difference between venous and whole body Hct. Relative changes in plasma volume were calculated according to the formula of Greenleaf et al. ${ }^{26}$

All subjects sat in a wheelchair in a thermoneutral room $\left(23^{\circ} \mathrm{C}\right.$ DB, $18^{\circ} \mathrm{C}$ WB $)$ while pre-immersion values ( -10 and $0 \mathrm{~min}$ ) were obtained. Subjects were then wheeled to the next room, transferred in the sitting position to a lightweight plastic chair, and lowered to the nipple line into an inground underwater weighing tank containing water controlled to $39^{\circ} \mathrm{C}$.

Each subject sat, suspended in water maintained at $39^{\circ} \mathrm{C}$ for up to $60 \mathrm{~min}$, until Tes reached $39^{\circ} \mathrm{C}$, or until he requested removal. A towel was positioned at the edge of the tank so that the subject could expectorate saliva. Tes and Tdp were recorded every $20 \mathrm{~s}$, and HR every $5 \mathrm{~min}$. Venous blood was withdrawn $-10,0,30$ and $60 \mathrm{~min}$ and was analysed as previously described. On subsequent and consecutive days (visits 3, 4, 5, 6 and 7), each subject returned at approximately the same time of day to sit immersed in water $\left(39^{\circ} \mathrm{C}\right)$ to the nipple line for $60 \mathrm{~min}$, until Toral reached $39^{\circ} \mathrm{C}$, or the subject requested to come out of the water. During each of these visits HR, and Toral measured sublingually via an AD590 with the mouth closed, were monitored throughout and recorded every $10 \mathrm{~min}$.

On visit 8, the day following the final passive heating session, the procedures described for visit 2 (the first immersion in $39^{\circ} \mathrm{C}$ water, pre-test) were repeated and reported as post-test. All visits to the laboratory occurred at approximately the same time of day for each subject and all passive heating sessions were conducted in an ambient environment of $25^{\circ} \mathrm{C}$ $\mathrm{DB}, 20^{\circ} \mathrm{C} \mathrm{WB}$.

The data are presented as means $(\overline{\mathrm{x}})$ and standard errors (SE). Dependent and independent $t$-tests were used to examine the differences between the groups. Analysis of variance with repeated measures (ANOVA) was used to compare data during pool immersion sessions and between pre- and post-test pool immersion sessions. If a significant ANOVA was obtained, a Scheffé post hoc test was used to determine which means were significantly different. The level chosen for statistical significance was $P<0.05$.

\section{Results}

Personal and anthropometric data are presented in Table 1. The paraplegic group (P) was significantly older $(37 \pm 4$ vs $22 \pm 1$ year) and lighter $(62.8 \pm 4$ vs $81.0 \pm 3.0 \mathrm{~kg}$ ) than the able-bodied group (AB), $(P<0.05)$. There was no significant difference in the skinfold thicknesses between the $\mathrm{P}$ and $\mathrm{AB}$ groups. The validity of equations relating sum of skinfold thicknesses, body density and per cent body fat in people who are paraplegic is equivocal. Accordingly, the present study chose to estimate adiposity by sum of skinfold thicknesses rather than using prediction equations for per cent body fat.

There were significant differences $(P<0.05)$ between the groups for the incremental exercise test to exhaustion, with the $\mathrm{AB}$ group having a higher $\mathrm{V}_{2}$ $\left(4.00 \pm 0.21\right.$ vs $2.23 \pm 0.12 \mathrm{~L} \mathrm{~min}^{-1}$ and $51.4 \pm 2.9$ vs $\left.35.4 \pm 1.4 \quad \mathrm{~mL} \mathrm{~kg}^{-1} \min ^{-1}\right) \quad \dot{\mathrm{VCO}}_{2} \quad 4.92 \pm 0.34 \quad v s$ $2.65 \pm 0.12\left(\mathrm{~L} \mathrm{~min}^{-1}\right)$ and VE BTPS $(132.3 \pm 13.4 v s$ $85.5 \pm 5.6\left(\mathrm{~L} \mathrm{~min}^{-1}\right)$. The HR max $\left(\mathrm{b} \min ^{-1}\right)$ was not significantly different between the $\mathrm{P}(185 \pm 3)$ and $\mathrm{AB}$ $(185 \pm 6)$ groups.

The heart rates at rest and at the end of immersion for both groups (P, AB) at pre test (visit 2) and posttest (visit 8) are presented in Table 2. There was no significant difference between the two groups in resting heart rate at either pre- or post-test sessions. For both groups and on both visits (pre- and post-tests) the heart rate at the end of immersion (60 min) was significantly higher than at rest $(P<0.05)$. The preand post-test heart rate at the end of immersion was not significantly different between the $\mathrm{AB}$ and $\mathrm{P}$ groups (Table 2).

Comparing pre- and post-test results for the $P$ group, there were no significant differences in Tes at rest $\left(36.72 \pm 0.10^{\circ} \mathrm{C}\right.$ vs $\left.36.75 \pm 0.37^{\circ} \mathrm{C}\right)$ or at the end of immersion $\left(38.15 \pm 0.10^{\circ} \mathrm{C}\right.$ vs $\left.38.07 \pm 0.17^{\circ} \mathrm{C}\right)$. For the AB group (pre- vs post-), there were no significant

Table 1 Personal and anthropometric characteristics of the subjects

\begin{tabular}{llcccc}
\hline Lesion & $\begin{array}{c}\text { Age } \\
\text { Subject } \\
\text { level }\end{array}$ & $\begin{array}{c}\text { Time in } \\
\text { chair } \\
\text { (years) }\end{array}$ & $\begin{array}{c}\text { Body } \\
\text { mass } \\
\text { (kg) }\end{array}$ & $\begin{array}{c}\text { Sum of } \\
\text { skinfolds } \\
\text { (mm) }\end{array}$ \\
\hline 1 & T10 & 45 & 27 & 63.3 & 23 \\
2 & T10 & 44 & 9 & 62.4 & 22 \\
3 & T6 & 41 & 34 & 78.4 & 37 \\
4 & T5 & 30 & 8 & 56.2 & 26 \\
5 & T12 & 25 & 5 & 53.6 & 14 \\
Mean & & 37 & & 62.8 & 24 \\
SE & & 4 & & 4 & 4 \\
6 & Able-bodied & 21 & & 88.8 & 31 \\
7 & Able-bodied & 21 & & 75.8 & 15 \\
8 & Able-bodied & 26 & & 77.8 & 27 \\
9 & Able-bodied & 22 & & 88.6 & 30 \\
10 & Able-bodied & 22 & & 74.2 & 18 \\
Mean & & 22 & & 81.0 & 24 \\
SE & & 1 & & 3.0 & 3 \\
\hline
\end{tabular}


Table 2 Heart rate (HR), oesophageal temperature (Tes) and sweat rate $(\mathrm{SR})$ for paraplegic $(\mathrm{P})$ and able-bodied (AB) groups during pre- $(\mathrm{P} 1)$ and post- $(\mathrm{P} 2)$ tests $(\overline{\mathrm{X}} \pm \mathrm{SE})$

\begin{tabular}{|c|c|c|}
\hline & P group & $A B$ group \\
\hline \multirow{2}{*}{$\begin{array}{l}\text { HR rest }(0 \min ) \\
\left(b \min ^{-1}\right)\end{array}$} & $64 \pm 4(\mathrm{P} 1)$ & $67 \pm 6(\mathrm{P} 1)$ \\
\hline & $74=$ & $(\mathrm{P} 2)$ \\
\hline \multirow{2}{*}{$\begin{array}{l}\text { HR end immersion } \\
\quad(60 \min )\left(\mathrm{b} \mathrm{min}^{-1}\right)\end{array}$} & $99 \pm 6(\mathrm{P} 1)$ & $104 \pm 7(\mathrm{P} 1)$ \\
\hline & $99=$ & $(\mathrm{P} 2)$ \\
\hline \multirow{2}{*}{$\begin{array}{l}\text { Tes rest }(0 \mathrm{~min}) \\
\left({ }^{\circ} \mathrm{C}\right)\end{array}$} & $36.72 \pm 0.10(\mathrm{P} 1)$ & $36.93 \pm 0.06(\mathrm{P} 1)$ \\
\hline & $36.75 \pm 0.37(\mathrm{P} 2)$ & $36.68 \pm 0.14(\mathrm{P} 2)$ \\
\hline \multirow{2}{*}{$\begin{array}{l}\text { Tes end immersion } \\
\quad(60 \mathrm{~min})\left({ }^{\circ} \mathrm{C}\right)\end{array}$} & $38.15 \pm 0.10(\mathrm{P} 1)$ & $38.77 \pm 0.11(\mathrm{P} 1)$ \\
\hline & $38.07 \pm 0.17(\mathrm{P} 2)$ & $38.24 \pm 0.10(\mathrm{P} 2)$ \\
\hline \multirow{2}{*}{$\begin{array}{l}\Delta \text { Tes }(\mathrm{T} 60-\mathrm{T} 0) \\
\left({ }^{\circ} \mathrm{C}\right)\end{array}$} & $1.42 \pm 0.08(\mathrm{P} 1)$ & $1.84 \pm 0.10(\mathrm{P} 1)$ \\
\hline & $1.27 \pm 0.09(\mathrm{P} 2)$ & $1.56 \pm 0.14(\mathrm{P} 2)$ \\
\hline \multirow{2}{*}{$\begin{array}{l}\text { Toral end immersion } \\
\qquad(60 \mathrm{~min})\left({ }^{\circ} \mathrm{C}\right)\end{array}$} & $38.3 \pm 0.2(\mathrm{P} 1)$ & $38.4 \pm 0.2(\mathrm{P} 1)$ \\
\hline & $38.2 \pm$ & $38.0 \pm 0.3(\mathrm{P} 2)$ \\
\hline \multirow{2}{*}{$\begin{array}{l}\text { Tes onset of sweating } \\
\left({ }^{\circ} \mathrm{C}\right)\end{array}$} & $37.32 \pm 0.2(\mathrm{P} 1)$ & $37.11 \pm 0.7(\mathrm{P} 1)$ \\
\hline & $37.11 \pm 0.3(\mathrm{P} 2)$ & $37.05 \pm 0.17(\mathrm{P} 2)$ \\
\hline \multirow{2}{*}{$\begin{array}{l}\mathrm{SR} \text { rest }+0.5^{\circ} \mathrm{C} \\
\quad\left(\mathrm{mg} \mathrm{min}{ }^{-1} \mathrm{~cm}^{-2}\right)\end{array}$} & $0.24 \pm 0.13(\mathrm{P} 1)$ & $0.17 \pm 0.04(\mathrm{P} 1)$ \\
\hline & $0.33 \pm 0.14(\mathrm{P} 2)$ & $0.30 \pm 0.19(\mathrm{P} 2)$ \\
\hline \multirow{2}{*}{$\begin{array}{l}\mathrm{SR} \text { rest }+1.0^{\circ} \mathrm{C} \\
\quad\left(\mathrm{mg} \mathrm{min} \min ^{-1} \mathrm{~cm}^{-2}\right)\end{array}$} & $0.66 \pm 0.19(\mathrm{P} 1)$ & $0.47 \pm 0.17(\mathrm{P} 1)$ \\
\hline & $0.24 \pm 0.14(\mathrm{P} 2)$ & $0.49 \pm 0.26(\mathrm{P} 2)$ \\
\hline
\end{tabular}

differences in Tes at rest $\left(36.93 \pm 0.06^{\circ} \mathrm{C}\right.$ vs $\left.36.68 \pm 0.14^{\circ} \mathrm{C}\right)$. The Tes in the $\mathrm{AB}$ group at the end of immersion was significantly lower at post-test $\left(38.24 \pm 0.10^{\circ} \mathrm{C}\right)$ than pre-test $\left(38.77 \pm 0.11^{\circ} \mathrm{C}\right)$ (Table $2)$. The rise in Tes from rest to end of immersion $(\Delta$ Tes) on both visits (pre- and post-tests) was significant for both groups $\mathrm{P}\left(1.42 \pm 0.08,1.27 \pm 0.09^{\circ} \mathrm{C}\right) \mathrm{AB}$ $\left(1.84 \pm 0.10,1.56 \pm 0.14^{\circ} \mathrm{C}\right)$. During the pre-test, the $\Delta$ Tes was significantly higher for the $A B$ group than the P group.

For the $\mathrm{P}$ group, the Tes $\left({ }^{\circ} \mathrm{C}\right)$ at which sweating commenced during pre- $\left(37.32 \pm 0.2^{\circ} \mathrm{C}\right)$ and post$\left(37.11 \pm 0.3^{\circ} \mathrm{C}\right)$ tests was not significantly different. The Tes $\left({ }^{\circ} \mathrm{C}\right)$ at which the onset of sweating occurred for the AB group was also not significantly different between pre- $\left(37.11 \pm 0.7^{\circ} \mathrm{C}\right)$ and post-tests $\left(37.05 \pm 0.17^{\circ} \mathrm{C}\right)$. (Table 2). As a guide to whether there had been any change in the rate of sweating from pre- to post-test sessions, sweat rates at 0.5 and $1.0^{\circ} \mathrm{C}$ above Tes rest, were calculated for both groups. There was no significant difference in the sweat rate occurring at 0.5 or $1.0^{\circ} \mathrm{C}$ above Tes rest during preand post-testing for $\mathrm{AB}$ or $\mathrm{P}$ subjects (Table 2).

Tes at pre- and post-tests and Toral during the second and sixth days of immersion for both groups $(\mathrm{AB}, \mathrm{P})$ are presented in Table 2. No significant differences were found between Tes and Toral for either group (AB, P) after 60 min of immersion when comparing the pre-test to immersion two results and post-test to immersion six results.

The hematological results for both groups at pre(visit 2) and post-test (visit 8) are presented in Table 3. During pre-testing there were no significant changes over time in hematocrit or hemoglobin concentration for either group. During post-testing, there were significant changes in Hct over time for the $\mathrm{P}$
Table 3 Hematocrit (Hct), hemoglobin ( $\mathrm{Hb}$ ) and plasma volume changes for paraplegic $(\mathrm{P})$ and able-bodied $(\mathrm{AB})$ groups during pre- and post-tests $(\overline{\mathrm{X}} \pm \mathrm{SE})$

\begin{tabular}{|c|c|c|c|c|}
\hline \multirow{2}{*}{$\begin{array}{l}\text { Time } \\
\text { (min) }\end{array}$} & \multicolumn{2}{|c|}{ P group } & \multicolumn{2}{|c|}{$A B$ group } \\
\hline & Pre & Post & Pre & Post \\
\hline & \multicolumn{2}{|c|}{ Hct $(\%)$} & \multicolumn{2}{|c|}{ Hct $(\%)$} \\
\hline-10 & $42.0 \pm 0.9$ & $42.0 \pm 0.5$ & $44.3 \pm 1.4$ & $44.4 \pm 1.5$ \\
\hline 0 & $41.2 \pm 0.8$ & $41.2 \pm 0.6$ & $43.4 \pm 2.0$ & $43.1 \pm 1.7$ \\
\hline 30 & $40.6 \pm 0.9$ & $40.4 \overline{ \pm} 1.1$ & $42.9 \pm 1.8$ & $42.4 \pm 1.8$ \\
\hline \multirow[t]{2}{*}{60} & $41.2 \pm 1.1$ & $40.1 \pm 0.8$ & $43.1 \pm 1.7$ & $43.5 \pm 1.8$ \\
\hline & \multicolumn{2}{|c|}{$H b\left(g d l^{-1}\right)$} & \multicolumn{2}{|c|}{$H b\left(g d l^{-1}\right)$} \\
\hline-10 & $15.5 \pm 0.4$ & $15.1 \pm 0.3$ & $15.6 \pm 0.5^{\circ}$ & $15.5 \pm 0.5$ \\
\hline 0 & $14.8 \pm 0.3$ & $14.8 \pm 0.2$ & $15.2 \pm 0.6$ & $15.2 \pm 0.6$ \\
\hline 30 & $14.8 \pm 0.3$ & $14.9 \pm 0.4$ & $15.4 \pm 0.7$ & $15.3 \pm 0.7$ \\
\hline \multirow[t]{2}{*}{60} & $14.8 \pm 0.3$ & $14.7 \pm 0.3$ & $15.7 \pm 0.7$ & $15.6 \pm 0.5$ \\
\hline & \multicolumn{2}{|c|}{$\Delta P V(\%)$} & \multicolumn{2}{|c|}{$\Delta P V(\%)$} \\
\hline$-10-0$ & $+6.1 \pm 2.0$ & $+3.2 \pm 1.4$ & $+4.7 \pm 2.5$ & $+5.3 \pm 2.5$ \\
\hline $0-30$ & $+7.0 \pm 2.1$ & $+4.0 \pm 3.9$ & $+3.2 \pm 3.3$ & $+4.6 \pm 3.9$ \\
\hline $30-60$ & $+3.9 \pm 3.1$ & $+3.4 \pm 4.8$ & $+1.5 \pm 3.7$ & $+0.5 \pm 2.4$ \\
\hline
\end{tabular}

(-10 min to $60 \mathrm{~min})$ and $\mathrm{AB}(-10 \mathrm{~min}$ to $30 \mathrm{~min})$ groups (Table 3$)$. The changes in plasma volume $(\Delta$ $\mathrm{PV} \%$ ) that occurred in both groups during pre- and post-tests are presented in Table 3. Both groups $(\mathrm{P}$, AB) significantly expanded their plasma volumes during pre- and post-testing $(P<0.05)$.

\section{Discussion}

The aim of the present study was to compare thermoregulatory responses to warm water $\left(39^{\circ} \mathrm{C}\right)$ immersion between physically active men who are paraplegic or able-bodied.

The present study used warm water immersion $\left(39^{\circ} \mathrm{C}\right)$ to the nipple line. This method of heating is practical, accessible and regulates the surface area available for evaporative cooling while maintaining a uniform skin temperature below the nipple line and a constant thermal load. Warm water is a commonly used rehabilitation medium after spiral cord injury.

The present study found no significant physiological adaptation in terms of lowered heart rate, and core temperature, nor an earlier onset and increased rate of sweating in the paraplegic (P) group. A significant post-test reduction in Tes after $60 \mathrm{~min}$ immersion was found in the able-bodied (AB) group.

The results of the present investigation partially agree with the findings of other warm water immersion studies, ${ }^{5,27}$ and are inconsistent with the results of most other studies using non aquatic environments as a heat stressor. ${ }^{5,7,28}$ All these previous studies investigated responses in able-bodied individuals. In seeking an explanation for the apparent inconsistency of the present results, the method and duration of applying the thermal load and composition of subject sample must be considered.

One factor to consider is the significant difference in body mass between the $\mathrm{P}$ and $\mathrm{AB}$ groups. This is to be 
expected, given that traumatic injury to the spinal cord interrupts efferent motor supply resulting in significant loss of lean body mass and subcutaneous fat below the level of the spinal cord lesion. This loss in the $\mathrm{P}$ group raises questions of differential rates of thermal insulation and therefore heat gain when both groups $(\mathrm{P}$ and $\mathrm{AB})$ are immersed to the nipple line in $39^{\circ} \mathrm{C}$ water, and suggests that the rate of heat gain could be higher in the $\mathrm{P}$ group compared to the $\mathrm{AB}$ group.

Previous studies have found that when humans with intact spinal cords are immersed in cold water $\left(17^{\circ} \mathrm{C}\right)$, heat loss is inversely proportional to the thickness of subcutaneous fat. ${ }^{29}$ It could be hypothesised that a similar inverse relationship could exist between the thickness of subcutaneous fat and rate of heat gain when immersed in water at $39^{\circ} \mathrm{C}$.

What separates this study from many other 'passive' heat studies is that the skin temperature below the nipple line was held constant at $39^{\circ} \mathrm{C}$ by a medium with high thermal conductivity (water). Yet, despite this constant skin temperature, significant differences in the rates of heat storage as estimated by $\Delta$ Tes were observed between $\mathrm{AB}$ and $\mathrm{P}$ groups. The rise in Tes from rest to end of immersion ( $\Delta$ Tes) for $\mathrm{AB}$ and $\mathrm{P}$ subjects during the pre-test immersion was $1.84 \pm 0.10$ and $1.42 \pm 0.08^{\circ} \mathrm{C}$ respectively indicating that for the same thermal load (water $39^{\circ} \mathrm{C}$ ) the heat gain in the $\mathrm{AB}$ subjects was higher than in the $\mathrm{P}$ subjects. A higher rate of heat gain was also found in the $\mathrm{AB}$ subjects during post-test immersion, albeit to a lesser absolute amount $\left(1.56 \pm 0.14^{\circ} \mathrm{C}(\mathrm{AB})\right.$ vs $1.27 \pm 0.09^{\circ} \mathrm{C}$ $(\mathrm{P})$ ). Dawson et $a l^{30}$ found that able-bodied and trained paraplegic subjects arm cranking at approximately $55 \%$ to $65 \% \mathrm{VO}_{2}$ max in a hot environment $\left(37.4 \pm 0.3^{\circ} \mathrm{C}, \mathrm{DB}, 33 \pm 2 \% \mathrm{RH}\right)$ had similar rates of heat storage (as estimated by $\Delta$ Trec) and sweating. The differences in the rate of heat storage reported by Dawson $e t a l^{30}$ and the present study may reflect the differences in thermal conductivity of water $\left(39^{\circ} \mathrm{C}\right)$ and air $\left(37^{\circ} \mathrm{C}\right)$ and differences in superficial body fat as estimated by sum of skinfold thicknesses.

Other factors that might explain the higher heat gain and heat storage in $\mathrm{AB}$ subjects in the present study are the larger skin surface area, an intact efferent nerve activity and less effective heat loss mechanisms. Although both groups were of a similar 'height', the significantly lower body mass in the $\mathrm{P}$ group would result in a smaller body surface area exposed to $39^{\circ} \mathrm{C}$ which may have contributed to a slower rate of heat gain. Although the surface area is seen as an important factor in heat gain/heat loss processes, when immersed in water, the major obstacle is the determination of convective heat gain. In the present study, the determination of convective heat gain is made difficult by the inclusion of subjects with spinal cord injury who could be expected to have different lower limb shapes, levels of insulation and neural innervation.

Although Tes at rest was similar for both groups at pre- and post-test, the higher rate of heat gain/storage in the $\mathrm{AB}$ group during pool immersion could reflect the presence of an intact efferent nerve activity in the lower limbs. With intact efferent nerve activity, active cutaneous vasodilatation and the associated increase in skin blood flow (SKBF) could be expected to contribute to a higher rate of convective heat exchange from the skin to the core. Support for this explanation has been provided by Bancroft et al, ${ }^{31}$ who found that sympathectomy prevented forearm vasodilatation. Further support for the relationship between an intact efferent nerve activity and active vasodilatation, albeit in the upper body, has been provided by others, ${ }^{32,33}$ who found that when the cutaneous nerves in the forearm were anaesthetised during body heating there was a reduction in SKBF. It could be argued that as a result of traumatic spinal cord injury, the lateral horn region of the thoracic spinal cord is damaged or higher centre control to this region is interrupted, leading to a sympathectomised state below the level of spinal cord lesion. The loss of efferent nerve activity would compromise the extent of active vasodilatation, and therefore skin blood flow. Taken together, it could be expected that in the $\mathrm{P}$ group a lower convective heat exchange from the skin to core would result in a slower heat gain and less heat storage. The final Tes for the $\mathrm{P}$ group was lower than the $\mathrm{AB}$ group at pre- and post-water immersion.

The lower rate of heat storage in the $\mathrm{P}$ group could also reflect differences in sudomotor function between the groups. Both groups could be expected to have active sweat glands above the water line and no useful sudomotor functioning or evaporative cooling below the water line. A previous $\operatorname{study}^{22}$ has raised the intriguing question that in those who have sustained a spinal cord injury, the neural drive to the remaining intact sweat glands may be higher for a given change in Tes. The increased rate of sweat production from those activated sweat glands above the water line, when coupled with the air environmental conditions surrounding the underwater weighing tank $\left(25^{\circ} \mathrm{C} \mathrm{DB}\right.$, $20^{\circ} \mathrm{C}$ WB), could have resulted in higher total evaporative heat loss in the $\mathrm{P}$ group and hence lower rate of heat storage. Although needing further experimentation, some support for the higher evaporative heat loss in the $\mathrm{P}$ group is found in Table 2, with the sweat rate for the $\mathrm{P}$ group being higher than the $\mathrm{AB}$ group during pre-immersion only, although not significantly.

For the $\mathrm{AB}$ group, the significantly lower $\Delta$ Tes at the post-test may be explained by the lower Tes at rest prior to the post-test (visit 8), and the approximately twofold increase in sweat rate $0.5^{\circ} \mathrm{C}$ above Tes at rest. The higher forehead sweat rate at post-test in $\mathrm{AB}$ group could have resulted in a higher evaporative loss, less thermal storage and a lower Tes at the end of post-test. The lower Tes at the end of $60 \mathrm{~min}$ post-test in the $\mathrm{P}$ group may be the result of differences in surface area efferent supply and sudomotor function, particularly in the areas of skin still maintaining 
sympathetic control, resulting in a higher evaporative heat loss.

In the present study, repeated warm water $\left(39^{\circ} \mathrm{C}\right)$ immersion had no significant effect on resting heart rate or heart rate at the end of immersion in either group. This finding is consistent with some results, but not with others. ${ }^{34}$ Those studies reporting a decrease in HR following repeating 'passive' heating, included air $^{34}$ and water perfused suits ${ }^{17}$ as the thermal stimulus. Those studies that have used repeated warm water immersion to affect a HR response are uniform in reporting no significant adaptive change in $\mathrm{HR}$ either at rest or at the end of immersion. ${ }^{27}$ This may not be surprising given that during warm water immersion, the HR responses may also be confounded by an expanded central blood volume and increased stroke volume. ${ }^{27,35,36}$

In those studies that reported significant physiological adaptation to 'passive' heating, the thermal load was often imposed via climatic chamber or temperature controlled water perfusion suits. The thermal load delivered by these methods was designed to achieve a Toral/Tympanic of $38^{\circ} \mathrm{C}$ for $1-2 \mathrm{~h}$, which was repeated daily for $9-15$ days. The present study imposed the thermal load by immersion in water $\left(39^{\circ} \mathrm{C}\right)$ calculated to raise Tcore to $38^{\circ} \mathrm{C}$ after $60 \mathrm{~min}$ and repeated for 5 days. The lower frequency of exposure (5 days) together with the shorter duration (60 min) could in part explain the lack of significant responses in the present study. Interestingly, Henane and Bittel $^{7}$ utilised a similar Tcore $\left(38^{\circ} \mathrm{C}\right)$, and duration of exposure $(60 \mathrm{~min})$ and after nine successive daily exposures $\left(45^{\circ} \mathrm{C}\right.$ dry bulb, $\left.24 \% \mathrm{RH}\right)$ found significant changes in Trec and in Trec at the onset of sweating. When daily bouts of exercise are completed in a hot environment $\left(49^{\circ} \mathrm{C}, 20 \% \mathrm{RH}\right.$, $100 \mathrm{~min}$ at $3.5 \mathrm{mph}$ ) some, if not all of the classical thermoregulatory changes are significant after 5-7 days. ${ }^{1}$

An important finding to emerge from the present study was the similarity of Tes and Toral in both groups $(\mathrm{AB}, \mathrm{P})$ after $60 \mathrm{~min}$ of immersion. In the absence of exercise, and after a suitable period of equilibration, Toral was a valid estimate of Tes in both $\mathrm{P}$ and $\mathrm{AB}$ groups.

\section{References}

1 Sawka MN, Wenger CB, Pandolf KB. Thermoregulatory responses to acute exercise-heat stress and heat acclimation. In: Fregly MJ, Blatteis CM (eds). Handbook of Physiology. Section 4. Environmental Physiology Vol 1. Oxford University Press: New York. 1996, pp 157-185.

2 Aukland K. Is extracellular fluid volume regulated? Acta Physiol Scand 1989; 136 (Suppl 583): 59-67.

3 Brebner DF, Kerslake D. The effect of soaking the skin in water on the acclimatisation produced by a subsequent heat exposure. $J$ Physiol 1963; 166: $13-14$.

4 Davies JA et al. Effect of saline loading during heat acclimatisation on adrenocortical hormone levels. $J$ Appl Physiol Respirat Environ Exercise Physiol 1981; 50: 605-612.
5 Fox RH, Goldsmith R, Hampton IFG, Lewis HE. The nature of the increase in sweating capacity produced by heat acclimatisation. J Physiol 1964; 171: $368-376$.

6 Guttman L, Silver J, Wyndham CH. Thermoregulation in spinal man. J Physiol Lond 1958; 142: $406-419$.

7 Henane R, Bittel J. Changes of thermal balance induced by passive heating in resting man. J Appl Physiol 1975; 38: 294-299.

8 Greenleaf JE, Reese RD. Exercise thermoregulation after 14 days of bed rest. J Appl Physiol Respirat Environ Exercise Physiol 1980; 48: $72-78$.

9 Hensel H. Neural processes in long-term thermal adaptation. Federation Proceedings 1981; 40: 2830-2834.

10 Armstrong LE, Costill DL, Fink WJ. Changes in body water and electrolytes during heat acclimation: effects of dietary sodium. Aviat Space Environ Med 1987; 58: 143 - 148.

11 Avellini BA, Kamon E, Krajewski JT. Physiological responses of physically fit men and women to acclimation to humid heat. $J$ Appl Physiol: Respirat Environ Exercise Physiol 1980; 49: $254-$ 261.

12 King DS, et al. Muscle metabolism during exercise in the heat in unacclimatised and acclimatised humans. J Appl Physiol 1985; 59: $1350-1354$

13 O'Toole ML, Paolone AM, Ramsay RE, Irion G. The effects of heat acclimation on plasma volume and plasma protein of females. Int J Sports Med 1983; 4: 40-44.

14 Pandolf KB, et al. Thermoregulatory responses of middle-aged and young men during dry-heat acclimation. J Appl Physiol 1988; 65: $65-71$.

15 Sawka MN et al. Influence of heat stress and acclimation on maximal aerobic power. Eur J Appl Physiol 1985; 53: 294-298.

16 Engel P. Laengsschnittuntersuchungen zur Hitzeanpassung durch systematisches Saunatraining. ZF Phys Med 6/8: 1979; 292-299.

17 Freund PR, Brengelmann GL, Rowell LB, Halar E. Attenuated skin blood flow response to hyperthermia in paraplegic men. $J$ Appl Physiol 1984; 56: $1104-1109$.

18 Randall WC, Wurster RD, Lewin RJ. Responses of patients with high spinal transection to high ambient temperatures. $J$ Appl Physiol 1966; 21: 985-993.

19 Gass GC, Camp EM. Effects of prolonged exercise in highly trained traumatic paraplegic men. J Appl Physiol 1987; 63: 18461852.

20 Gass GC et al. Rectal and rectal vs oesophageal temperatures in paraplegic men during prolonged exercise. J Appl Physiol 1988; 64: $2265-2271$.

21 Normell LA. Distribution of impaired cutaneous vasomotor and sudomotor function in paraplegic man. Scand J Clin Lab Invest 1974; (Suppl) 30 138: $25-41$.

22 Silver JR, Randall WC, Guttmann L. Spinal mediation of thermally induced sweating. J Neurol Neurosurg Psych 1991; 54: $297-304$

23 Calder CJ, Kirby RL. Fatal wheelchair related accidents in the United States, Am J Phys Med Rehab 1990; 69: 184-190.

24 Graichen H, Rascati R, Gonzales R. Automatic dew-point temperature sensor. J Appl Physiol: Respirat Environ Exercise Physiol 1982; 52: $1658-1660$.

25 Drabkin DL, Austen LH. Spectrophotometric Studies II. Preparations from washed blood cells: nitric oxide hemoglobin and sulfhemoglobin. $J$ Biol Chem 1935; 112: 51-65.

26 Greenleaf JE, Convertino VA, Mangseth GR. Plasma volume during stress in man: osmolality and red cell volume. $J$ Appl Physiol 1979; 47: 1031-1038.

27 Arborelius M, Balldin UI, Lilja BI, Lundgren CEG. Hemodynamic changes in man during immersion with the head above water. Aerospace Med 1972; 43: $592-598$.

28 Bonner RM, Harrison MH, Hall CJ, Edwards RJ. Effect of heat acclimatisation on intravascular responses to acute heat stress in man. J Appl Physiol 1976; 41: 708 -713.

29 McDonald A, Goode RC, Livingston SD, Duffin J. Body cooling in human males by cold-water immersion after rigorous exercise. Undersea Biomed Res 1984; March, 81-90.

30 Dawson B, Bridle J, Lockwood RJ. Thermoregulation of paraplegic and able bodied men during prolonged exercise in hot and cool environments. Paraplegia 1994; 32: 360-370. 
31 Bancroft HW, Bonnar WM, Edholm OG. Reflex vasodilation in human skeletal muscle in responses to heating the body. $J$ Physiol (Lond) 1947; 106: $271-278$.

32 Edholm OG, Fox RH, McPherson RK. Vasomotor control of the cutaneous blood vessels in the human forearm. J Physiol (Lond) 1957; 139: 455 - 465

33 Roddie IC, Shepherd JT, Whelan RF. The contribution of constrictor and dilator nerves to the skin vasodilation during body heating. J Physiol (Lond) 1957; 136: 489-497.
34 Convertino VA, Greenleaf JE, Embernauer A. Role of thermal and exercise factors in the mechanism of hyperthermia. $J \mathrm{Appl}$ Physiol 1980; 48: 657-664.

35 Aoyagi Y, McLellan TM, Shephard RJ. Interaction of physical training and heat acclimation; the thermophysiology of exercising in a hot climate. Sport Med 1997; 23: 173-210.

36 Greenleaf JE. Physiological responses to prolonged bed rest and fluid immersion in humans. J Appl Physiol 1984; 57: 619-633. 